\title{
Bile Pigment Excretion: A Comparison of the Biliary Excretion of Bilirubin and Bilirubin Derivatives*
}

\author{
Roger Lester † and Peter D. Klein with the tech nical assistance of \\ Armand M. Matusen \\ (From the Fifth and Sixth [Boston University] Medical Services, Boston City Hospital, and \\ the Department of Medicine, Boston University School of Medicine, Boston Uni- \\ versity Medical Center, Boston, Mass., and from the Division of Biological \\ and Medical Research, Argonne National Laboratory, \\ Argonne, Ill.)
}

During the process of hepatic excretion, a diverse group of exogenous organic compounds and endogenous metabolites is conjugated with polar anionic molecules (1). Although it is clear that the physical and chemical characteristics of these compounds can be drastically altered by conjugation, the relationship between conjugation and excretion has not been fully elucidated (2). Formation of the glucuronide conjugate appears to be an essential step in the excretion of bilirubin (3-5). Gunn rats, a congenitally jaundiced mutant species of Wistar rats, have a partial deficiency of glucuronyl transferase activity for several substrates and an essentially complete inability to form bilirubin glucuronide $(6,7)$. As a result they are incapable of excreting significant quantities of bilirubin in the bile (8), although their capacity to excrete exogenously administered bilirubin glucuronide is undisturbed (9), and in other respects hepatic function is normal.

In the course of studying the enterohepatic circulation of mesobilirubinogen ${ }^{14} \mathrm{C}$ we observed that a Gunn rat excreted three-quarters of a 1.9$\mathrm{mg}$ dose of this bilirubin derivative within $90 \mathrm{~min}$ utes of intravenous administration (10). This finding, which suggested that mesobilirubinogen was not excreted as the glucuronide conjugate, was unexpected in view of the apparent similarity be-

* Submitted for publication May 26, 1966; accepted August 12, 1966.

Supported in part by the U. S. Atomic Energy Commission and the U. S. Public Health Service (grants AM 07091 and AM 09881).

† Recipient of U. S. Public Health Service Development Award 12,127.

Address requests for reprints to Dr. Roger Lester, Boston University School of Medicine, 80 East Concord St., Boston, Mass. 02118. tween mesobilirubinogen and bilirubin (Figure 1). To determine whether a relationship exists among molecular structure, conjugation, and excretion, we prepared a series of tritiated bile pigments and administered it intravenously to rats with external biliary drainage. We determined the rate of biliary excretion of these compounds and established whether they are excreted in bile as the glucuronide conjugate.

\section{Methods}

Preparation of radioactive compounds. Radiochemically pure, specifically labeled bilirubin- ${ }^{8} \mathrm{H}$ was prepared biosynthetically by techniques described previously (11).

Mesobilirubin was labeled with tritium by catalytic reduction of unlabeled bilirubin $(12 a)$ in the presence of tritium gas. For this purpose $50 \mathrm{mg}$ of crystalline bilirubin was mixed with $10 \mathrm{mg}$ of palladium black (99\%) in a small hydrogenation vessel equipped with a magnetic stirrer and dropping funnel. Into the funnel was placed several milliliters of $0.1 \mathrm{~N} \mathrm{NaOH}$, and the apparatus was evacuated and filled with tritium gas obtained by the electrolysis of $15 \% \mathrm{KOH}$ in tritiated water, SA $36 \mathrm{mc}$ per mmole. The catalyst was equilibrated for 30 minutes, and $3 \mathrm{ml}$ of the $\mathrm{NaOH}$ solution was added dropwise with stirring. The deep red mixture was stirred for 3 hours, during which $40 \mathrm{ml}$ of tritium gas (theory $37.9 \mathrm{ml}$ ) was taken up, and the solution changed to a light yellow color. The solution was acidified with glacial acetic acid, and the yellow pigment was extracted into chloroform. The chloroform extracts were washed with water, dried over sodium sulfate, and evaporated to dryness. The yellow pigment was crystallized and recrystallized by displacement of chloroform with boiling methanol. The yield of crystalline material equaled $34 \%$ of the starting material. On spectrophotometric examination, the end product showed maximal absorption at 433 $\mathrm{m} \mu$ [absorption maximum of mesobilirubin in chloroform $=434 \mathrm{~m} \mu$ (13) ] ; a diazo derivative was prepared (14a) with maximal absorption at $540 \mathrm{~m} \mu$. The specific activity of mesobilirubin- ${ }^{8} \mathrm{H}$ equaled $7.7 \mathrm{mc}$ per mmole, and it remained constant on repeated recrystallization. 


\section{BILIRUBIN}

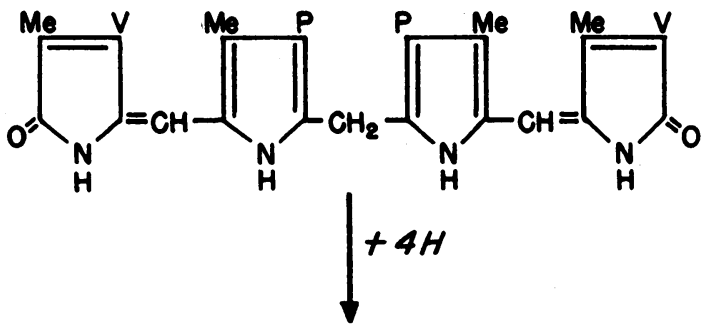

MESOBILIRUBIN

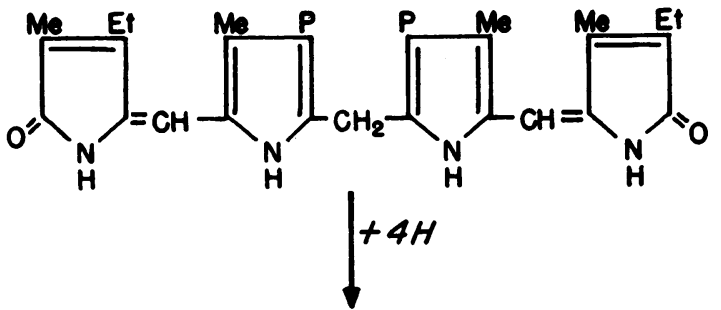

MESOBILIRUBINOGEN

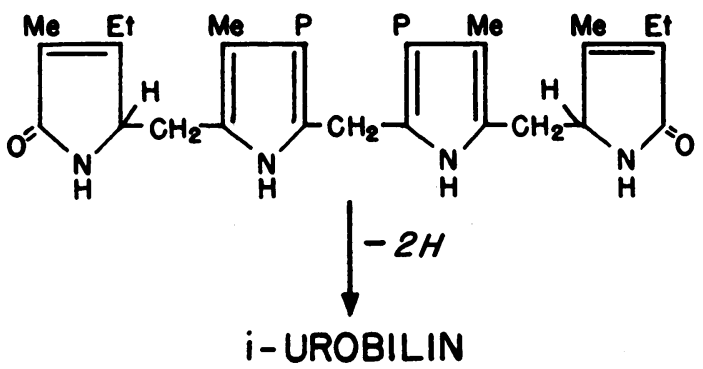

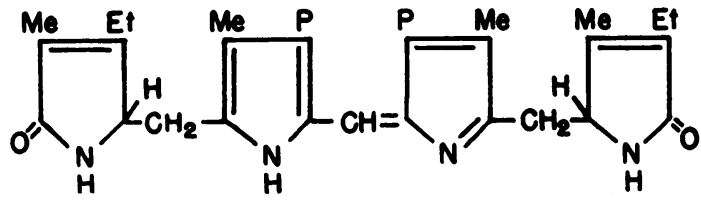

Fig. 1. Schematic Representation of the CONVERSION OF BILIRUBIN SUCCESSIVELY TO MESOBILIRUBIN, MESOBILIRUBINOGEN, AND OPTICALLY INACTIVE (i)-UROBILIN. $\mathrm{Me}=$ methyl $; \mathrm{Et}=$ ethyl $; \mathrm{V}=$ vinyl $; \mathrm{P}=$ propionic acid.

Mesobilirubinogen- ${ }^{3} \mathrm{H}$ was prepared by sodium amalgam reduction according to the method of Fischer and Orth $(12 b)$ by substituting $2 \mathrm{ml}$ of tritiated water, SA $54 \mathrm{mc}$ per mmole, in the reaction mixture. The colorless amorphous mesobilirubinogen- ${ }^{8} \mathrm{H}$ was crystallized from hot ethyl acetate and stored in evacuated tubes, in the dark, at $-20^{\circ} \mathrm{C}$. The yield of amorphous powder equaled $60 \%$, but only $10 \%$ of the end product was obtained in crystalline form. On addition of Ehrlich reagent and saturated sodium acetate, the tritiated chromogen formed a characteristic urobilinogen-aldehyde complex with maximal absorption at $557 \mathrm{~m} \mu$ [absorption maximum of urobilinogen-aldehyde $=556 \mathrm{~m} \mu \quad$ (15)]. The SA of mesobilirubinogen- ${ }^{3} \mathrm{H}$ equaled $42 \mathrm{mc}$ per mmole, and within the limits of the methodology employed, the specific activities of amorphous, crystalline, and recrystallized mesobilirubinogen were equal (10).

Mesobilirubinogen $-{ }^{8} \mathrm{H}$ dissolved in petroleum ether was oxidized to optically inactive (i)-urobilin $-{ }^{3} \mathrm{H}$ hydrochloride according to the method of Watson (16). This redorange pigment was crystallized and recrystallized by displacement of methanol with boiling ethyl acetate. The yield of crystalline end product equaled $10 \%$ of the mesobilirubinogen $-{ }^{3} \mathrm{H}$. Because of the low yield, it was convenient to add unlabeled mesobilirubinogen (prepared by techniques similar to those described above) to the starting material to obtain enough pigment for crystallization. When $i$-urobilin- ${ }^{8} \mathrm{H}$ hydrochloride was dissolved in $3 \% \mathrm{HCl}$ in methanol, maximal absorption occurred at $493 \mathrm{~m} \mu$ [absorption maximum of $i$-urobilin hydrochloride in $3 \%$ hydrochloric acid in methanol $=494 \mathrm{~m} \mu$ $(14 b)$ ], and characteristic green fluorescence was obtained on addition of zinc acetate to methanolic solutions (14c). The maximal SA obtained was $1 \mathrm{mc}$ per mmole, and the specific activity remained constant on repeated crystallization.

Administration of tritiated compounds. Male SpragueDawley C.D. rats and congenitally jaundiced Gunn rats were prepared with an external biliary fistula. Weighed samples of tritiated pigments and pigment derivatives were dissolved in $0.1 \mathrm{~N} \mathrm{NaOH}$, and the basic solution was added gradually and with stirring to rat serum. The serum was neutralized and administered to the rats by rapid intravenous injection. With the rats under continued ether anesthesia, the bile was collected during 15minute periods for a total of 90 minutes with collection tubes changed at 15-minute intervals. All samples were collected in subdued light at $4^{\circ} \mathrm{C}$, and when possible, analysis of the specimens was performed immediately upon completion of the experiment.

Analytical methodology. Chromatography of the diazo pigments of bilirubin and mesobilirubin was performed according to the method of Schmid (4). After development of the chromatograms, conjugated diazo pigments were eluted from the paper in $1 \mathrm{~N}$ acetic acid, and the eluates were taken to dryness in vacuo. The dried pigment was dissolved in a small volume of $1 \mathrm{~N}$ acetic acid, and $0.1 \mathrm{ml}$ was incubated at $37^{\circ} \mathrm{C}$ for 6 to 12 hours under nitrogen with $30,000 \mathrm{U}$ of bacterial $\beta$-glucuronidase $^{1}$ and $2.5 \mathrm{ml}$ of $0.2 \mathrm{~N}$ acetate buffer $\mathrm{pH} 5.0$ (total volume of incubation mixture, $3.0 \mathrm{ml}$ ). On completion of incubation, the solution was acidified and extracted with butanol; the extracted pigment was then rechromatographed. Mixtures of crystalline (unconjugated) bilirubin and mesobilirubin were applied to Whatman $3 \mathrm{~mm}$ paper in 5 - to $10-\mu \mathrm{g}$ quantities and separated by chromatography (17) in system I [ascending, chloroform: petroleum ether $(1: 9)]$. The chromatogram was divided into strips and counted in a liquid scintillation counter. Mesobilirubinogen and $i$-urobilin were extracted from acidified bile into chloroform, and 1- to 4- $\mu \mathrm{g}$ quantities were chromatographed on Whatman $3 \mathrm{~mm}$ paper

1 Sigma Scientific Co., St. Louis, Mo. 
in the following solvent systems: system II, ascending, methanol : butanol : ammonia $(1: 3: 2)$ (17); system III, ascending, ethyl acetate: octanol $(1: 1$, saturated with ammonia) (18); system IV, descending, butanol : pyridine: water $(1: 1: 1)$. The chromatograms were dried, sprayed with zinc acetate in methanol, and examined under fluorescent light to identify the compounds and to calculate their $\mathbf{R}_{\mathbf{f}}$.

Bilirubin and mesobilirubin were crystallized from bile according to the method of Ostrow, Hammaker, and Schmid (19). $i$-Urobilin was extracted into chloroform from acidified bile and crystallized from methanol-ethyl acetate as described above. Mesobilirubinogen in bile specimens was oxidized with ferric chloride and hydrochloric acid and then crystallized as $i$-urobilin. Bile specimens and crystals were counted in a liquid scintillation spectrometer, and the results were analyzed statistically by methods described previously (20).

\section{Results}

Rate of tetrapyrrole excretion in normal and Gunn rats. After the intravenous administration of 23 or $238 \mu \mathrm{g}$ of bilirubin- ${ }^{3} \mathrm{H}$ to two normal (Sprague-Dawley, C.D.) rats, excretion of the label was evident during the first 15 minutes, and by 90 minutes 79 to $86 \%$ of the radioactive dose had appeared in bile. When comparable amounts

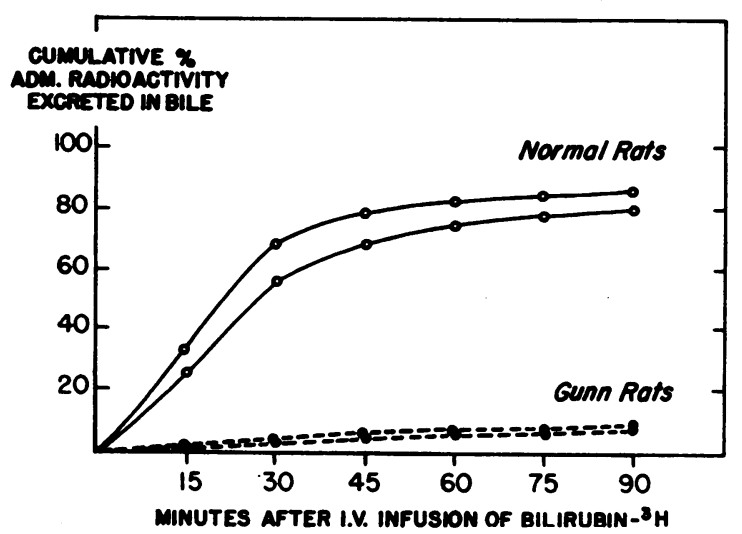

Fig. 2. RAdioACtivity IN BILE AFTER INTRAVENOUS ADMINISTRATION OF BILIRUBIN- ${ }^{8} \mathrm{H}$.

of bilirubin- ${ }^{3} \mathrm{H}$ were administered to two Gunn rats, less than $10 \%$ of the radioactive dose was excreted (Figure 2, Table I). Similar results were obtained with mesobilirubin- ${ }^{3} \mathrm{H}$ (Figure 3, Table I). From 71 to $80 \%$ of administered mesobilirubin- ${ }^{3} \mathrm{H}$ was excreted by four normal rats within 90 minutes, whereas 10 and $2 \%$ was excreted by two Gunn rats during an identical time period.

TABLE I

Biliary excretion of labeled tetrapyrroles

\begin{tabular}{|c|c|c|c|c|c|c|c|}
\hline \multirow[b]{2}{*}{ Experiment } & \multirow{2}{*}{$\begin{array}{c}\text { Type of } \\
\text { rat }\end{array}$} & \multirow[b]{2}{*}{ Wt } & \multicolumn{3}{|c|}{ Characteristics of dose } & \multirow[b]{2}{*}{ Amount } & \multirow{2}{*}{$\begin{array}{l}\text { Radioactivity } \\
\text { excreted in } \\
\text { bile in } 90 \mathrm{~min}\end{array}$} \\
\hline & & & Tetrapyrrole administered & Vol & Radioactivity & & \\
\hline $\begin{array}{l}1 \\
2 \\
3 \\
4\end{array}$ & $\begin{array}{l}\text { S.D.* } \\
\text { S.D. } \\
\text { Gunn } \\
\text { Gunn }\end{array}$ & $\begin{array}{c}g \\
430 \\
400 \\
350 \\
400\end{array}$ & 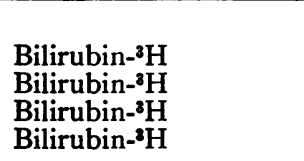 & $\begin{array}{l}m l \\
1.1 \\
2.0 \\
1.2 \\
1.0\end{array}$ & $\begin{array}{l}d p m \\
458,000 \\
759,000 \\
196,000 \\
179,000\end{array}$ & $\begin{array}{r}\mu g \\
238 \\
23 \\
25 \\
22\end{array}$ & $\begin{array}{c}\text { \% dose } \\
79 \\
86 \\
8 \\
8\end{array}$ \\
\hline $\begin{array}{r}5 \\
6 \\
7 \\
8 \\
9 \\
10\end{array}$ & $\begin{array}{l}\text { S.D. } \\
\text { S.D. } \\
\text { S.D. } \\
\text { S.D. } \\
\text { Gunn } \\
\text { Gunn }\end{array}$ & $\begin{array}{l}460 \\
430 \\
400 \\
460 \\
400 \\
400\end{array}$ & 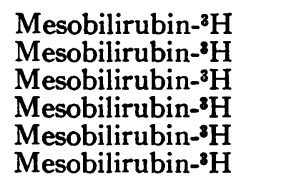 & $\begin{array}{l}1.9 \\
2.8 \\
4.4 \\
1.5 \\
1.5 \\
1.1\end{array}$ & $\begin{array}{r}137,000 \\
245,000 \\
336,000 \\
46,000 \\
101,000 \\
811,000\end{array}$ & $\begin{array}{r}369 \\
660 \\
906 \\
124 \\
272 \\
29\end{array}$ & $\begin{array}{r}76 \\
74 \\
70 \\
71 \\
2 \\
10\end{array}$ \\
\hline $\begin{array}{l}11 \\
12 \\
13 \\
14 \\
15 \\
16 \\
17 \\
18\end{array}$ & $\begin{array}{l}\text { S.D. } \\
\text { S.D. } \\
\text { S.D. } \\
\text { S.D. } \\
\text { S.D. } \\
\text { S.D. } \\
\text { Gunn } \\
\text { Gunn }\end{array}$ & $\begin{array}{l}340 \\
330 \\
330 \\
360 \\
460 \\
450 \\
410 \\
400\end{array}$ & 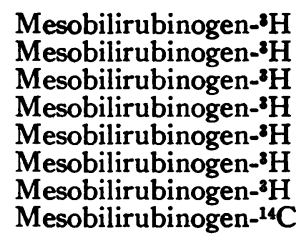 & $\begin{array}{l}0.7 \\
2.6 \\
0.3 \\
0.4 \\
3.4 \\
3.4 \\
0.9 \\
1.4\end{array}$ & $\begin{array}{r}513,000 \\
497,000 \\
11,654,000 \\
313,000 \\
746,000 \\
4,753,000 \\
780,000 \\
197,000\end{array}$ & $\begin{array}{r}3 \\
3 \\
70 \\
2 \\
498 \\
3,146 \\
10 \\
1,900\end{array}$ & $\begin{array}{l}74 \\
75 \\
85 \\
79 \\
83 \\
95 \\
92 \\
88\end{array}$ \\
\hline $\begin{array}{l}19 \\
20 \\
21 \\
22 \\
23\end{array}$ & $\begin{array}{l}\text { S.D. } \\
\text { S.D. } \\
\text { Gunn } \\
\text { Gunn } \\
\text { Gunn }\end{array}$ & $\begin{array}{l}430 \\
430 \\
350 \\
400 \\
420\end{array}$ & 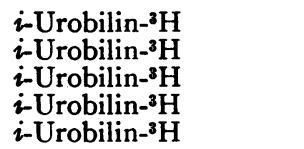 & $\begin{array}{l}1.2 \\
1.7 \\
1.2 \\
1.3 \\
1.1\end{array}$ & $\begin{array}{r}1,020,000 \\
272,000 \\
218,000 \\
461,000 \\
495,000\end{array}$ & $\begin{array}{r}310 \\
333 \\
93 \\
197 \\
606\end{array}$ & $\begin{array}{l}69 \\
72 \\
82 \\
85 \\
83\end{array}$ \\
\hline
\end{tabular}

* Sprague-Dawley. 


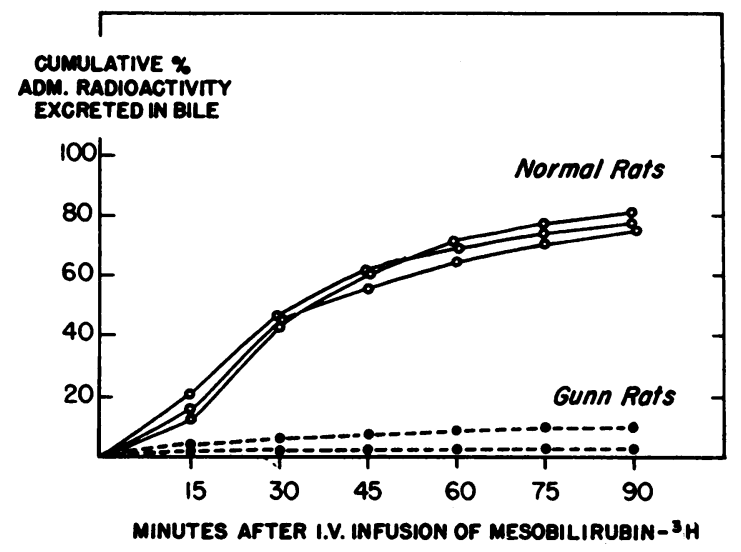

Fig. 3. RADIOACTIVITY IN BILE AFTER INTRAVENOUS ADMINISTRATION OF MESOBILIRUBIN $-{ }^{8} \mathrm{H}$.

In contrast to the findings with bilirubin and mesobilirubin, mesobilirubinogen- ${ }^{3} \mathrm{H}$ and $i$-urobilin- ${ }^{3} \mathrm{H}$ were excreted readily by both normal and Gunn rats (Figures 4 and 5, Table I). The low cost and the high specific activity of mesobilirubinogen- ${ }^{3} \mathrm{H}$ made it possible to examine the rate of hepatic excretion for an extremely wide range of doses. Within 90 minutes of intravenous injection, the normal rats excreted 74 to $95 \%$, and two Gunn rats 88 to $92 \%$ of microgram to milligram amounts of mesobilirubinogen- ${ }^{3} \mathrm{H} .{ }^{2}$ After administration of 310 to $333 \mu \mathrm{g}$ of $i$-urobilin- ${ }^{3} \mathrm{H}$ to two normal rats, 69 to $72 \%$ of the radioactive dose appeared in bile, and three Gunn rats excreted 82 to $85 \%$ of a comparable dose. As shown in Figures 2 to 5 , the early phase of excretion in

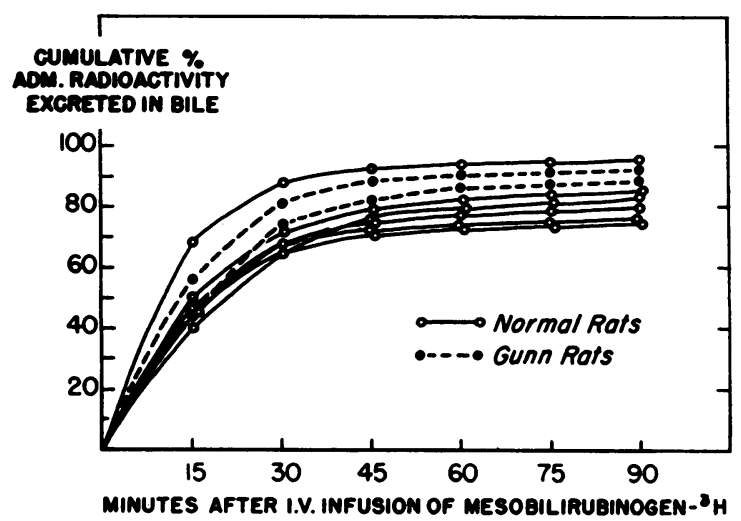

Fig. 4. Radioactivity in Bile after intravenous ADMINISTRATION OF MESOBILIRUBINOGEN $-{ }^{3} \mathrm{H}$.

2 Data from one Gunn rat study performed with mesobilirubinogen $-{ }^{14} \mathrm{C}$ and described previously (10) are included. normal rats was more rapid for mesobilirubinogen ${ }^{3} \mathrm{H}$ and $i$-urobilin- ${ }^{3} \mathrm{H}$ than for bilirubin- ${ }^{3} \mathrm{H}$ and mesobilirubin $-{ }^{3} \mathrm{H}$. This observation is in accord with previous findings obtained during double label studies of the relative rates of excretion of bilirubin- ${ }^{3} \mathrm{H}$ and mesobilirubinogen- ${ }^{14} \mathrm{C}$ (11).

Identification of excreted tetrapyrroles. After administration of bilirubin- ${ }^{3} \mathrm{H}, 85$ to $100 \%$ of the radioactive label appearing in bile could be hydrolyzed and then crystallized as bilirubin ${ }^{3} \mathrm{H}$. Chromatography of the diazo pigment derivative of this material established that 90 to $92 \%$ was present in bile in the form of conjugated bilirubin. Comparable results were obtained after injection of mesobilirubin ${ }^{3} \mathrm{H}$. Seventy to $80 \%$ of the ex-

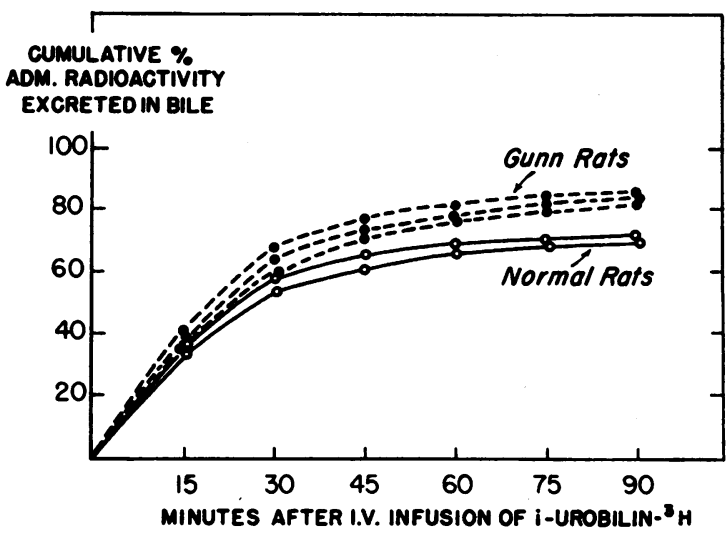

Fig. 5. Radioactivity IN BILE AFter INTRAVENOUS ADMINISTRATION OF I-UROBILIN $-{ }^{3} \mathrm{H}$.

creted material was diazo reactive and could be crystallized from bile in a mixture with endogenous bilirubin. When this mixture was chromatographed in system $I$, and compared with crystalline samples of bilirubin ${ }^{3} \mathrm{H}$ and mesobilirubin ${ }^{3} \mathrm{H}$, more than $85 \%$ of the material applied to the paper was identified as mesobilirubin ${ }^{3} \mathrm{H}$. The diazo pigment derivative of excreted mesobilirubin was chromatographed in the system devised by Schmid for the chromatography of unconjugated and conjugated bilirubin (4). Eighty-eight to $92 \%$ of the identifiable pigment migrated with an $R_{\mathbf{f}}$ identical to that of bilirubin glucuronide. Control markers of the diazo derivative of unconjugated mesobilirubin migrated at the same rate as the diazo derivative of unconjugated bilirubin. After incubation of the material presumed to be the diazo derivative of conjugated mesobilirubin 
with $\beta$-glucuronidase, all of the identifiable pigment migrated with an $R_{f}$ identical to that of unconjugated bilirubin and unconjugated mesobilirubin.

In bile samples taken from rats 15,16 , and 18 given intravenous mesobilirubinogen- ${ }^{3} \mathrm{H}, 95$ to $103 \%$ of the administered radioactive dose was present in the form of Ehrlich-reactive chromogen. Seventy to $84 \%$ of the Ehrlich-reactive chromogen could be extracted from acidified bile into petroleum ether: ethyl ether $(9: 1)$. This recovery equaled that obtained in three control experiments, in which crystalline mesobilirubinogen ${ }^{-3} \mathrm{H}$ was dissolved directly in rat bile and extracted into petroleum ether-ethyl ether. Thirty to $45 \%$ of the radioactivity in bile samples treated with ferric chloride and hydrochloric acid could be crystallized as urobilin. Chloroform extracts of acidified bile obtained from experiments 15,16 , and 18 (Table I) were chromatographed in systems II to IV, and, because of oxidation of mesobilirubinogen to urobilin on exposure to air and the solvent system, the point of migration could be identified by spraying the chromatogram with methanolic zinc acetate. The $R_{f}$ obtained on chromatography of bile extracts equaled the $R_{\mathbf{f}}$ of control samples of crystalline (unconjugated) mesobilirubinogen and were comparable to values previously reported for $i$-urobilin (18).

Similar results were obtained with $i$-urobilin- ${ }^{3} \mathrm{H}$. Fifty to $60 \%$ of the radioactivity appearing in bile could be extracted into chloroform and identified spectrophotometrically and by crystallization as urobilin. When the chloroform extracts of bile obtained in experiments 19, 20, 22, and 23 (Table I) were developed chromatographically in solvent systems II to IV, the $R_{f}$ obtained matched the $\mathrm{R}_{\mathrm{f}}$ of control $i$-urobilin markers.

\section{Discussion}

On the basis of earlier reports and the results described above, it can be concluded that significant differences exist in the mechanisms by which bile pigments and their derivatives are excreted. On the one hand, bilirubin is excreted by the liver as the diglucuronide (3-5); on the other, the experiments described above suggest that both mesobilirubinogen and $i$-urobilin are excreted, at least in part, as the intact unconjugated tetrapyrrole.
The techniques for the isolation and identification of mesobilirubinogen and $i$-urobilin are by no means as satisfactory as those employed for bilirubin. Whereas the availability of labeled compounds permitted accurate assessment of rates of excretion, identification of excreted metabolites was limited to those experiments in which more than $150 \mu \mathrm{g}$ of mesobilirubinogen- ${ }^{3} \mathrm{H}$ or $i$-urobilin${ }^{3} \mathrm{H}$ was administered. It should be emphasized that, because of the limitations of methodology, we made no attempt to identify minor fractions of labeled compounds excreted in the bile. Our studies do not exclude the possibility that some mesobilirubinogen or $i$-urobilin is excreted conjugated with glucuronide or other sugar moieties as has been suggested previously (21).

Within these limitations, we established that the major proportion of mesobilirubinogen was excreted in bile intact and unaltered. The excreted material was Ehrlich reactive and could be oxidized to urobilin. That most of this material was not mesobilirubinogen glucuronide was indicated by the fact that two-thirds to three-quarters could be extracted into the nonpolar solvent petroleum ether-ethyl ether $(9: 1)$. Mesobilirubinogen extracted from the bile of rats receiving the tritiated chromogen intravenously migrated chromatographically at the same rate as crystalline (unconjugated) mesobilirubinogen. Finally, when mesobilirubinogen $-{ }^{3} \mathrm{H}$ was administered to Gunn rats, 88 and $92 \%$ of the dose was excreted in bile within 90 minutes of injection. Although it is conceivable that Gunn rats have a normal complement of "mesobilirubinogen glucuronyl transferase," the possibility appears remote.

The relative stability and ease of crystallization of $i$-urobilin permitted a more direct examination of the mechanism of its excretion. After intravenous administration of the tritiated pigment, approximately one-half of the material appearing in the bile could be identified spectrophotometrically and by crystallization as intact $i$-urobilin. Pigment extracted from bile migrated chromatographically in three solvent systems with $R_{f}$ identical to those of crystalline $i$-urobilin. As with mesobilirubinogen, Gunn rats excreted three-quarters of the administered $i$-urobilin- ${ }^{8} \mathrm{H}$ over a dose range of 93 to $606 \mu \mathrm{g}$. In fact, during the period from 30 to 90 minutes after injection, Gunn rats appeared to excrete $i$-urobilin- ${ }^{3} \mathrm{H}$ more effectively 
than normal rats, and a similar but less pronounced trend was observed in studies of mesobilirubinogen- ${ }^{3} \mathrm{H}$ excretion (Figures 4 and 5 ). The apparent lower rate of excretion among normal rats might be explained as the result of competitive inhibition of mesobilirubinogen and $i$-urobilin excretion by endogenous bilirubin (22). Competitive inhibition would be of a much lower order of magnitude in Gunn rats, which are incapable of excreting appreciable quantities of bilirubin (8). The limited availability of Gunn rats prevented the performance of an adequate number of experiments for valid statistical confirmation of this trend, but it is clear that Gunn rats excrete mesobilirubinogen and $i$-urobilin at least as effectively as normal rats.

In view of their apparent similarity (Figure 1), it is somewhat surprising that bilirubin is excreted almost exclusively as the glucuronide, whereas the major fraction of mesobilirubinogen and $i$-urobilin is excreted without conjugation. The side chains of each of the tetrapyrroles are in so-called IXa sequence $(14 d)$, and a carbonyl group is attached to the free $\alpha$ position of each of the outer pyrrole rings. The formula of each tetrapyrrole differs from the others only in the degree of saturation of its double bonds. Each is weakly acidic at physiologic $\mathrm{pH}$; with the exception of $i$-urobilin, each is maximally soluble in chloroform and minimally soluble in water. Bilirubin and $i$-urobilin have chromophoric centers consisting of systems of resonating conjugated double bonds. Bilirubin and mesobilirubinogen have four protonated pyrrole nitrogens, and $i$-urobilin has three. The physiologic behavior of the members of the series has several features in common. After intravenous injection, each is cleared rapidly from the plasma, taken up by the hepatic parenchyma, and secreted at high concentrations in bile.

Despite the apparent similarities, however, an examination of the molecular formulas shown in Figure 1 reveals that essentially two differences exist between the depicted structures of bilirubin, on the one hand, and mesobilirubinogen and $i$-urobilin on the other. In the former, the inner and outer pyrrole rings are joined by unsaturated (methyne) carbon-carbon linkages [bridges a and c according to accepted nomenclature $(14 e, 23)]$, whereas in mesobilirubinogen and $i$-urobilin these positions are saturated (methene). Secondly, in bilirubin the second and eighth side chain groups are unsaturated (vinyl), whereas in mesobilirubinogen and $i$-urobilin these side chains are saturated (ethyl). The intermediate compound mesobilirubin appeared to provide a test of whether the presence of unsaturated outer bridges determines which tetrapyrroles form glucuronides, or whether unsaturation of the side chains is the determining factor. Mesobilirubin cannot be isolated from biologic materials (17) but can be synthesized by the catalytic reduction of bilirubin in vitro $(12 a)$. The vinyl side chains of bilirubin are saturated by the reduction, but the outer carbon bridges remain unsaturated (Figure 1).

The pattern of excretion of mesobilirubin- ${ }^{3} \mathrm{H}$ was strikingly similar to that of bilirubin- ${ }^{8} \mathrm{H}$. Excretion by Gunn rats was defective, and normal rats excreted mesobilirubin- ${ }^{3} \mathrm{H}$ as the glucuronide conjugate. This result would be predicted if it were assumed that the conjugation of tetrapyrroles depends upon the presence or absence of unsaturation in bridges a and $c$. It should be noted that the results do not exclude the possibility that, rather than unsaturation at positions a and $c$ being significant, the point of differentiation between the two groups of compounds is the presence of two unsaturated bridges per se. Thus, it would be necessary to administer labeled tetrapyrroles with a,b or b,c unsaturation (e.g., mesobiliviolin, mesobilierythrin) to prove that the a,c configuration is specific. Unfortunately, the structure of these compounds and their preparative chemistry have not, at present, been developed sufficiently to permit purification and physiologic investigation.

Any explanation of the relationship between the conjugating mechanism and the presence of methyne a,c bridges must remain speculative. Nevertheless, one can distinguish several major effects of unsaturation at these positions on the resultant pigment and pigment derivatives. By constructing Dreiding molecular models of the tetrapyrrole series one can readily demonstrate that the limitation of rotation introduced by unsaturation of these bridges (as in bilirubin and mesobilirubin) results in a marked degree of molecular "rigidity." Since free rotation can occur around saturated carbon-carbon bonds, however, molecular models of mesobilirubinogen and $i$-urobilin exhibit a much higher degree of flexi- 
bility. Several lines of evidence suggest that internal hydrogen bonding occurs in some or all of the molecules of the series. The rigidity introduced by methyne a,c bridges would be expected to influence the ease with which hydrogen bonds form between the side chain carboxyls and the hydrogen atoms attached to ring nitrogens (24), or between the carbonyl oxygens of the outer rings and the hydrogen atoms of the ring nitrogens (25). Moreover, the presence of unsaturation at positions a,c should further influence hydrogen binding at the carbonyl oxygen atoms by extending the system of resonating conjugated double bonds to include both the inner and the outer pyrrole rings. By effecting changes in internal (or external) hydrogen bonding, the presence of methyne or methene bridges might further modify molecular configuration and thereby influence the biologic behavior of individual tetrapyrroles.

It is tempting to speculate that the configurational differences conferred by saturation or unsaturation of the a,c bridges influence the "fit" of the tetrapyrrole to the secretory carrier. The more flexible molecules (mesobilirubinogen and $i$-urobilin) might fit the secretory carrier directly, whereas the more rigid members of the series (bilirubin and mesobilirubin) might have to be modified by conjugation in order to permit a fit. On the other hand, the physical-chemical characteristics of all four tetrapyrroles are altered by the degree of saturation of the outer bridges. Those tetrapyrroles that are saturated at positions a,c have lower melting points and are more water soluble than the other members of the series. Rather than specifically modifying secretory carrier fit, the physical-chemical changes introduced by alteration of the outer bridges may influence the mechanism of excretion by limiting penetration of the molecules to the site of the carrier or by influencing other stages in the complex excretory process. To determine the relative contribution of each of these factors, we are now studying the excretion of other polypyrrolic compounds.

One additional observation should be made on the relationship between a,c unsaturation and glucuronide conjugation. Treatment of the diazo derivative of bilirubin glucuronide results in the formation of a hydroxamate derivative (26). Since hydroxamate formation is limited to carboxyl (acyl) glucuronides (27), it is generally accepted that bilirubin is conjugated by esterification of its propionic acid carboxyls (28). On the other hand, final proof of this assumption by the isolation of bilirubin glucuronide and direct analysis of its structure has not yet been advanced. When a comparison is made to steroid conjugates, the extreme instability of conjugated bilirubin more closely resembles an enol- than an esterglucuronide (29). Unsaturation of the a,c bridges extends the conjugation of the double bond system to include both the outer and inner pyrrole rings. Because of this and because of their closer proximity to the carbonyl (keto-enol) group than to the propionic acid side chains, the effect of unsaturation of bridges a and $c$ is more likely to be on the former. Our evidence that alterations in these bridges influence the mechanism of conjugation suggests that the question of the site of bilirubin conjugation should be re-examined.

\section{Summary}

The mechanism of excretion of four tetrapyrroles-bilirubin, mesobilirubin, mesobilirubinogen, and optically inactive ( $i$ )-urobilin-was studied in normal and Gunn rats. For this purpose ${ }^{3} \mathrm{H}-\mathrm{la}$ beled tetrapyrroles were prepared, and their radiochemical purity was established. On intravenous administration, each was rapidly excreted in bile by normal rats, but only mesobilirubinogen and $i$-urobilin were excreted in substantial quantities by Gunn rats. In the normal species studied, $90 \%$ of the bilirubin and mesobilirubin excreted was in the form of the glucuronide conjugate. In contrast, a major fraction of excreted mesobilirubinogen and $i$-urobilin appeared in the bile intact and unaltered.

These findings suggest that glucuronide conjugation of bile pigments may be governed by a specific molecular configuration: unsaturation of the outer $(a, c)$ tetrapyrrole bridges.

\section{Acknowledgments}

The authors wish to thank Dr. Rudi Schmid and Dr. Sidney $R$. Cooperband for their thoughtful and constructive criticism of the manuscript.

\section{References}

1. Williams, R. T. Detoxication Mechanisms; The Metabolism and Detoxication of Drugs, Toxic Substances, and Other Organic Compounds, 2nd ed. London, Chapman \& Hall, 1959. 
2. Wheeler, H. O. The function of the biliary tract in Progress in Liver Diseases, H. Popper and F. Schaffner, Eds. New York, Grune \& Stratton, 1965, vol. 2, pp. 15-25.

3. Billing, B. H., P. G. Cole, and G. H. Lathe. Excretion of bilirubin as a diglucuronide giving the direct van den Bergh reaction. Biochem. J. 1957, $65,774$.

4. Schmid, R. The identification of "direct-reacting" bilirubin as bilirubin glucuronide. J. biol. Chem. 1957, 229, 881.

5. Talafant, E. Properties and composition of the bile pigment giving a direct diazo reaction. Nature (Lond.) 1956, 178, 312.

6. Carbone, J. V., and G. M. Grodsky. Constitutional nonhemolytic hyperbilirubinemia in the rat: defect of bilirubin conjugation. Proc. Soc. exp. Biol. (N. Y.) 1957, 94, 461.

7. Axelrod, J., R. Schmid, and L. Hammaker. A biochemical lesion in congenital, non-obstructive, nonhæmolytic jaundice. Nature (Lond.) 1957, 180, 1426.

8. Schmid, R., J. Axelrod, L. Hammaker, and R. L. Swarm. Congenital jaundice in rats, due to a defect in glucuronide formation. J. clin. Invest. 1958, 37, 1123.

9. Arias, I. M., L. Johnson, and S. Wolfson. Biliary excretion of injected conjugated and unconjugated bilirubin by normal and Gunn rats. Amer. J. Physiol. 1961, 200, 1091.

10. Lester, R., and R. Schmid. Intestinal absorption of bile pigments. III. The enterohepatic circulation of urobilinogen in the rat. J. clin. Invest. 1965, 44, 722 .

11. Lester, R., and P. D. Klein. Biosynthesis of tritiated bilirubin and studies of its excretion in the rat. J. Lab. clin. Med. 1966, 67, 1000.

12. Fischer, H., and H. Orth. Die Chemie des Pyrrols. Leipzig, Akademische Verlagsgesellschaft, 1937, vol. $2, a)$ p. $650, b)$ p. 692 .

13. Gray, C. H., A. Kulczycka, and D. C. Nicholson. The chemistry of the bile pigments. III. Prototropy of bilirubin to a verdinoid pigment. J. chem. Soc. 1961, 2268.

14. Lemberg, R., and J. W. Legge. Hematin Compounds and Bile Pigments; Their Constitution, Metabolism, and Function. New York, Intersci- ence, $1949, a)$ p. $121, b)$ p. $140, c)$ p. $139, d)$ p. 55 , e) p. 107 .

15. Heilmeyer, L. Spectrophotometry in Medicine. London, Adam Helger, 1943, p. 219.

16. Watson, C. J. The direct preparation of crystalline urobilin from bilirubin. J. biol. Chem. 1953, 200, 691.

17. Pearson, L. B., Jr., and C. J. Watson. A study of the reported occurrence of mesobilirubin in human bile. Proc. Soc. exp. Biol. (N. Y.) 1963, 112, 756.

18. Royer, M., B. B. Lozzio, and S. Gorodisch. Chromatographic separation and proportional determination of $l-, i$-, and $d$-urobilins. Acta physiol. lat.-amer. 1964, 14, 94.

19. Ostrow, J. D., L. Hammaker, and R. Schmid. The preparation of crystalline bilirubin- $\mathrm{C}^{\mathbf{1 4}}$. J. clin. Invest. 1961, 40, 1442.

20. Lester, R., and R. Schmid. Intestinal absorption of bile pigments. I. The enterohepatic circulation of bilirubin in the rat. J. clin. Invest. 1963, 42, 736.

21. Kahan, I. L. Studies on urobilinoids. Studia Medica Szegedinensia 1961, 1 (no. 2), 1.

22. Hunton, D. B., J. L. Bollman, and H. N. Hoffman II. The plasma removal of indocyanine green and sulfobromophthalein: effect of dosage and blocking agents. J. clin. Invest. 1961, 40, 1648.

23. Gray, C. H. Bile Pigments in Health and Disease. Springfield, Il1., Charles C Thomas, 1961, p. 3.

24. Fog, J., and E. Jellum. Structure of bilirubin. Nature (Lond.) 1963, 198, 88.

25. Moscowitz, A., W. C. Krueger, I. T. Kay, G. Skewes, and S. Bruckenstein. On the origin of the optical activity in the urobilins. Proc. nat. Acad. Sci. (Wash.) 1964, 52, 1190.

26. Schacter, D. Nature of the glucuronide in directreacting bilirubin. Science 1957, 126, 507.

27. Schacter, D. The chemical estimation of acyl glucuronides and its application to studies on the metabolism of benzoate and salicylate in man. J. clin. Invest. 1957, 36, 297.

28. Lester, R., and R. Schmid. Bilirubin metabolism. New Engl. J. Med. 1964, 270, 779.

29. Wakabayashi, M., H. H. Wotiz, and W. H. Fishman. Action of $\beta$-glucuronidase on a steroid-enol- $\beta$-glucosiduronic acid. Biochim. biophys. Acta (Amst.) 1961, 48, 198. 